\title{
The role of positive psychology constructs in predicting life satisfaction in adolescents with and without cognitive disabilities: An exploratory study
}

\author{
KARRIE A. SHOGREN, SHANE J. LOPEZ, MICHAEL L. WEHMEYER, \\ TODD D. LITTLE, \& CINDY L. PRESSGROVE \\ University of Kansas, USA
}

\begin{abstract}
Positive psychology has begun to foster change in the study of adolescence by directing increased attention to the importance of building on adolescents' strengths and abilities as a means to promote positive outcomes. The purpose of this study was to explore the associations between hope, optimism, locus of control, self-determination, and life satisfaction in adolescents with and without cognitive disabilities using structural equation modeling. The results demonstrated comparability in the measurement of each of these constructs in adolescents with and without disabilities. Hope, optimism, locus of control, and self-determination were strongly correlated, and hope and optimism predicted life satisfaction in adolescents with and without cognitive disabilities. The implications of the findings for future research are discussed.
\end{abstract}

Keywords: Hope; optimism; self-determination; locus of control; life satisfaction; cognitive disability

\section{Introduction}

In recent years increased attention has been directed toward positive psychology (Seligman, 1998; Seligman \& Csikszentmihalyi, 2000) and the need for a fundamental shift in the focus of psychological research. As Seligman (1999) stated in his President's Address to the American Psychological Association, "psychology has moved too far away from its original roots, which were to make the lives of all people more fulfilling and productive" (p. 559). The tendency of psychological research to focus on distress, pathology, and maladaptive functioning rather than on strengths, abilities, and optimal functioning is clearly demonstrated in the study of adolescence. Research has tended to focus on youth's problem behavior and the prevention of negative outcomes, such as teen pregnancy, violence, eating disorders, academic difficulties, and suicide, rather than on youth's strengths and abilities and the promotion of positive outcomes, such as happiness, life satisfaction, resiliency, and initiative (Huebner, 2004; Larson, 2000; Rich, 2003). However, the growing body of scholarship focusing on supporting and enhancing the development of adolescents' strengths and abilities (Chafouleas \& Bray, 2004; Huebner, 2004; Hunter \& Csikszentmihalyi, 2003; Larson, 2000;
Pajares, 2001; Rich, 2003; Roberts, Brown, Johnson, \& Reinke, 2002; Snyder et al., 2002) suggests that positive psychology has begun to foster change by directing increased attention to the importance of research focusing on promoting positive outcomes, rather than preventing negative outcomes, in adolescence.

Positive psychology is also fostering change in the study of adolescents with cognitive disabilities. Traditionally, research with adolescents with cognitive disabilities has been narrowly focused on deficits in functioning and on negative outcomes that result from these deficits (e.g., learned helplessness, negative perceptions of control, and academic failure). However, Schalock (2004) identified positive psychology as a component of the "emerging disability paradigm" (p. 204) because of its implications for organizing conceptions of personal well-being in people with intellectual disabilities. And the growing body of research on promoting strengths in adolescents with disabilities (Clark, Olympia, Jensen, Heathfield, \& Jenson, 2004; Grant, Ramcharan, \& Goward, 2003; McCullough \& Huebner, 2003) suggests that the positive psychology movement has brought increased attention to the importance of building on positive characteristics as a means to promote valued outcomes in adolescents both with and without disabilities. 
Positive psychology research, however, is still in its infancy and, to some degree, still occurs in relative isolation. As Judge (2003, p. 3) stated:

Someone may be doing a research program on one trait or characteristic ... [and] someone else may be carrying on a parallel research program... One really can't build on the other unless the commonality between them is acknowledged... It makes it very difficult to make sense of the literature, and what the relationship is among these traits.

Further, given positive psychology's goal of broadening the scope of research and practice in psychology and fostering cross-disciplinary linkages (Seligman \& Csikszentmihalyi, 2000; Snyder \& Lopez, 2002), there are many more programs of research to examine for commonalities than in the past. Thus, as Snyder and Lopez (2002) stated regarding the future of positive psychology, "greater attention needs to be paid to the overlap of constructs so as to ascertain shared operative processes and the shared variance in optimal functioning" (p. 756).

Moreover, despite the acknowledgement in the literature that a focus on positive psychology can provide a new direction for research and practice pertaining to people with disabilities, there is little research to move that agenda forward. Therefore, as the field moves forward, we need to work to bring together parallel research programs, not only in psychology, but also in its related disciplines and fields, to examine what is shared and what is unique in the positive psychology movement and to examine the relevance and implications of positive psychology constructs for all people, including people with disabilities.

Thus, the purpose of this study, which is part of an ongoing research initiative examining the effect of positive psychology interventions for adolescents with and without cognitive disabilities, was to bring together parallel lines of research from different fields that focus on promoting positive outcomes in adolescents. Specifically, we were interested in examining the comparability of and interrelationships between some of the most extensively studied positive psychology constructs (hope, optimism, locus of control, and life satisfaction) and selfdetermination, a psychological construct that has been applied to both the disciplines of positive psychology and special education (Wehmeyer, 1996a, 2001; Wehmeyer, Abery, Mithaug, \& Stancliffe, 2003; Wehmeyer, Palmer, Agran, Mithaug, \& Martin, 2000).

Hope theory (Snyder, 1994; Snyder et al., 1991) assumes that human actions are goal directed (Snyder, Rand, \& Sigmon, 2002). Within the theory, hope is defined as "goal-directed thinking in which people perceive that they can produce routes to desired goals (pathways thinking) and the requisite motivation to use those routes (agency thinking)" (Lopez, Snyder, \& Teramoto-Pedrotti, 2003, p. 94). People with high hope tend to be successful in their goal pursuits and, as a result, tend to experience more positive emotions. People with low hope tend to have more difficulty in overcoming the barriers to goal attainment and, therefore, tend to experience more negative emotions (Lopez et al., 2003; Snyder et al., 2002). These emotions, and the learning histories that foster them, then influence future goal pursuits. In defining optimism, Carver and Scheier $(2002,2003)$ focus on an expectancyvalue model of motivation, and assume, as in hope theory, that behavior is organized around the pursuit of goals. According to their theory, optimists pursue goals that have value to them and have confidence that they will be able to attain these goals. Pessimists, on the other hand, tend to not have the expectancy that they can achieve their goals, and therefore tend not to act towards their goals. Thus, a person's outcome expectancies (similar to agency thinking in hope theory; Snyder et al., 2002) are seen as critical to the performance of goal directed behavior (Carver \& Scheier, 1998; Scheier \& Carver, 1992).

Rotter (1966), in defining the locus of control construct, suggested that a person's expectation of specific reinforcement in a given situation depends more on their attitude toward the situation rather than the situation itself.

When a reinforcement is perceived by the subject as following some action of his own but not being entirely contingent upon his action... we have labeled this a belief in external control. If the person perceives that the event is contingent upon his own behavior or his own relatively permanent characteristics, we have termed this a belief in internal control (Rotter, 1966, p. 1).

People who perceive a causal relationship between their actions in a given situation and the outcomes they experience (i.e., an internal locus of control orientation), tend to have a greater action capacity than people who perceive outside forces (i.e., an external locus of control orientation) as having control over the outcomes they experience in a given situation.

Life satisfaction has been defined as "a global evaluation by the person of his or her life" (Pavot, Diener, Colvin, \& Sandvik, 1991, p. 150), and has been identified as a key aspect of quality of life and subjective well-being. Positive life satisfaction has been linked with a variety of adaptive outcomes, and is viewed both as an important outcome and 
as a potential contributor to the development of other positive behaviors and attitudes (Huebner, 2004).

In our research pertaining to the self-determination construct within the special education field (Wehmeyer, 1996a, 1999), we have defined selfdetermined behavior as "acting as the primary causal agent in one's life and making choices and decisions regarding one's quality of life free from undue external influence or interference" (Wehmeyer, 1996a, p. 24). Self-determined behavior refers to behavior whose function is to enable the person to act as a causal agent in their lives. The essential characteristics of self-determined behavior include autonomy, self-regulation, psychological empowerment, and self-realization (Wehmeyer, 1999). That is, people who are self-determined, who are causal agents in their own lives, act autonomously and are self-regulating, psychologically empowered, and selfrealizing. Snyder and Lopez (2002) identified this "functional" theory of self-determination as a part of the "future of positive psychology" (p. 751). However, there are no studies, of which we are aware, applying the functional theory of selfdetermination to students without disabilities, and very few studies applying positive psychological constructs like optimism (Carver \& Scheier, 2002; Scheier et al., 1994; Scheier, Weintraub, \& Carver, 1986) and hope (Snyder, 1994; Snyder et al., 1991; Snyder, Rand, et al., 2002) to students with cognitive disabilities. And, while both locus of control (Fournier \& Jeanrie, 2003; Nowicki \& Strickland, 1973) and life satisfaction (Diener, Emmons, Larson, \& Griffin, 1985; Diener, Lucas, \& Oishi, 2002; Gilman, Huebner, \& Laughlin, 2000; Huebner, 1994) have been studied in adolescents with and without cognitive disabilities (DudleyMarling, Snider, \& Tarver, 1982; Huebner, Ash, \& Laughlin, 2001; Wehmeyer, 1993a, 1994c), there have been no studies, to our knowledge, that have simultaneously evaluated the relationships between self-determination, hope, optimism, locus of control, and life satisfaction, in students with and without cognitive disabilities. However, these constructs appear to have significant overlap. For example, the functional theory of self-determination identifies locus of control as one of the elements that contributes to psychological empowerment (Wehmeyer, Abery, et al., 2003). Further, optimism (Carver \& Scheier, 2002, 2003) and hope theory's (Snyder, Rand, et al., 2002) focus on goal-directed behavior overlaps with the focus on self-regulation and psychological empowerment in the functional theory of self-determination (Wehmeyer, Abery, et al., 2003).

In addition to examining the comparability of and relationships between these positive psychology constructs in adolescents with and without cognitive disabilities, we also sought to evaluate the degree to which hope, optimism, self-determination and locus of control predicted life satisfaction. Life satisfaction has been identified as an important outcome for adolescents with and without disabilities (Huebner, 2004), and, as mentioned above, an important component of perceptions of subjective well-being (Diener et al., 2002) and quality of life (Huebner, 2004; Huebner, Suldo, Smith, \& McKnight, 2004). Life satisfaction has also been related to school functioning (Huebner \& Alderman, 1993; Huebner \& McCullough, 2000) and a decreased likelihood of externalizing behaviors (McKnight, Huebner, \& Suldo, 2002; Suldo \& Huebner, 2004a, 2004b). Hope and optimism have, in previous research, been found to contribute to adolescent's life satisfaction (Edwards, 2004). Research has also suggested a relationship between locus of control and life satisfaction (Ash \& Huebner, 2001; Dew \& Huebner, 1994; Huebner, 1991). For example, Huebner (1991) found that students who reported high life satisfaction also tended to score more adaptively on measures of locus of control, and Ash and Huebner (2001) found that locus of control mediated the relationship between acute negative life events and chronic stressors and life satisfaction in adolescents. And, although the functional theory of self-determination has never been evaluated in terms of its contribution to life satisfaction, it has been shown to contribute to a more positive quality of life (Wehmeyer \& Schwartz, 1998) and to positive postschool outcomes for youth with cognitive disabilities (Wehmeyer \& Palmer, 2003; Wehmeyer \& Schwartz, 1997). Thus, we sought to further this knowledge base and examine the role of hope, optimism, and locus of control, as well as the potential role of the functional theory of self-determination, in predicting adolescent's life satisfaction.

Because this study represents one of the first efforts to examine the self-determination construct (as conceptualized in research in special education) in students without disabilities, and one of only a few efforts to examine the hope and optimism constructs in students with disabilities, we chose to use the technique of structural equation modeling (SEM) because of its flexibility in allowing us to examine equivalence issues related to the measurement of each construct in adolescents with and without cognitive disabilities as well as potential cross-group differences in the latent relationships among the constructs. Specifically, we were interested in the following research questions:

(1) Can strong metric invariance of the manifest indicators across the disability and no disability groups be established in the measurement of autonomy, self-regulation, psychological 
empowerment, self-realization (essential characteristics of self-determination), agency thinking, pathways thinking (subdomains of hope), optimism, locus of control, and life satisfaction? That is, does invariance of the loadings and intercepts hold (Little, 1997; Meredith, 1993)?

(2) What is the pattern of interrelationships among autonomy, self-regulation, psychological empowerment, self-realization (essential characteristics of self-determination), agency thinking, pathways thinking (subdomains of hope), optimism, locus of control, and life satisfaction in adolescents with and without cognitive disabilities?

(3) Are there mean level differences in autonomy, self-regulation, psychological empowerment, self-realization (essential characteristics of self-determination), agency thinking, pathways thinking (subdomains of hope), optimism, locus of control, and life satisfaction in adolescents with and without cognitive disabilities?

(4) Do hope, optimism, self-determination, and locus of control predict life satisfaction in adolescents with and without cognitive disabilities?

\section{Method}

\section{Procedures}

School personnel (e.g., school psychologists, school counselors, transition specialists, general and special education teachers, and school principles) within districts across the state of Kansas were contacted by study personnel and provided information about the purpose and nature of this study. School personnel from 12 schools, representing urban, semi-urban, and rural districts, agreed to participate. Participating school personnel were asked to identify students who were eligible to participate (i.e., students who did not receive special education services and students who received special education services under the label of learning disability or mild/ moderate mental retardation), and obtain informed consent for participation from the student's parent/ guardian. All the necessary materials, along with instructions for the administration of the various rating scales, were distributed to school personnel by project staff. After informed consent was received, along with assent from the student, the school personnel administered the battery of assessments in individual or group settings. For students with cognitive disabilities, support (i.e., reading questions or deciphering words) was provided as needed by school personnel. However, school personnel were advised to only assist with questions regarding item content, not questions regarding the appropriate way to answer items.

\section{Participants}

Participants included 285 students without cognitive disabilities and 75 students with cognitive disabilities in grades $7-12$. Students with cognitive disabilities received special education services under the categories of learning disability or mild/moderate mental retardation. No further demographic information on the participants was available to the researchers.

\section{Measures}

Self-determination. The Adolescent Self-Determination Assessment (ASDA; Wehmeyer \& Lopez, 2003) was used to measure self-determination. The ASDA is a revision of a measure of self-determination widely used in special education research. The Arc's Self-Determination Scale (Wehmeyer \& Kelchner, $1995)$ is a 72 -item self-report measure that provides data on self-determination through the measurement of the four essential characteristics of self-determined behavior: autonomy, self-regulation, psychological empowerment, and self-realization (Wehmeyer, 1996a). Subscale scores can be calculated for the autonomy, self-regulation, psychological empowerment, and self-realization domains, as well as a total self-determination score. A total of 148 points are available on the scale, with higher scores indicating higher levels of self-determination. The Arc's SelfDetermination Scale was developed and normed with 500 adolescents with cognitive disabilities (Wehmeyer, 1996b). It was demonstrated to have adequate reliability and validity in the measurement of self-determination for adolescents with cognitive disabilities.

The Arc's Self-Determination Scale was developed primarily for use with adolescents with cognitive disabilities. The ASDA was developed to provide a valid and reliable measure for all adolescents, with and without cognitive disabilities. Scale developers began by modifying items on The Arc's SelfDetermination Scale that might be perceived by adolescents without cognitive disabilities as too simple. Once this version was developed, a focus group of adolescents without disabilities discussed the scales items, item-by-item, providing recommendations for revisions. These revisions were incorporated into the final version. Wehmeyer, Lopez, Shogren, and Pressgrove (2005) evaluated the psychometric properties of the Adolescent SelfDetermination Assessment, and determined that the factor structure of the measure replicated, to a large extent, that of the original measure and was 
consistent with the theoretical framework upon which the original scale was based. In this study, Cronbach's alpha values for the ASDA were 0.89 for students without disabilities, and 0.87 for students with cognitive disabilities.

Hope. The Children's Hope Scale (CHS; Snyder et al., 1997) was used to assess hope in students with and without cognitive disabilities. The CHS is a 6-item self-report measure that assesses agency and pathways thinking. Two subscale scores (agency and pathways) or a total hope score can be calculated. Total hope scores can range from 6 to 36, with higher scores indicating greater levels of hope. Research has demonstrated that the CHS has adequate reliability and validity for use in students without cognitive disabilities ages 7-16. Cronbach's alpha values for the scale in this study were 0.89 and 0.87 for students without disabilities and for students with cognitive disabilities, respectively.

Optimism. Optimism was measured using the Life Orientation Test-Revised (LOT-R; Scheier et al., 1994). The LOT-R consists of six items (and four additional filler items not included in scoring); three framed in an optimistic and three framed in a pessimistic manner. Total scores range from 6 to 30, with higher scores indicating greater optimism. The LOT-R has been demonstrated to have good reliability and internal consistency in youth without disabilities (Scheier et al., 1994). Cronbach's alpha values for the scale were 0.75 for students without disabilities and 0.56 for students with cognitive disabilities.

Locus of control. The Nowicki-Strickland InternalExternal Scales (ANS-IE; Nowicki \& Duke, 1974) was used to assess locus of control orientations in students with and without cognitive disabilities. The ANS-IE is one of the most widely used assessments of locus of control. It consists of 40 items measured with a yes/no response; total scores can range from 0 to 40, with higher scores indicating a more external orientation. The ANS-IE was normed for use with students without disabilities; however, it has also been used extensively with students with cognitive disabilities, and demonstrated to have adequate reliability in this population (Hall, Spruill, \& Webster, 2002; Thomas \& Pashley, 1982; Wehmeyer, 1993b, 1994a, 1994c). Further, Wehmeyer (1993a) demonstrated comparability in the factor structure of the ANS-IE when administered to youth and adults with and without cognitive disabilities. Cronbach's alpha values in this study were 0.73 for students without disabilities and 0.72 for students with cognitive disabilities.

Life satisfaction. To measure life satisfaction, multiple measures were used, including the Satisfaction With Life scale (SWL; Diener et al., 1985) and the Self and Global subscales of the Multidimensional Life Satisfaction Scale (MSLSS; Huebner, 1994; Huebner, Laughlin, Ash, \& Gilman, 1998). The SWL scale consists of five questions; total scores can range from 5 to 30, with higher scores indicating greater satisfaction with life. The SWL has been demonstrated to have adequate reliability and validity for youth without disabilities (Diener et al., 1985). In this study, Cronbach's alpha values for the SWL were 0.86 for students without disabilities, and 0.81 for students with cognitive disabilities. The MSLSS is a 47-item self-report measure of life satisfaction across five specific life domains (family, friends, school, living environment, and self) as well as a global domain (i.e., questions not pertaining to any specific life domain). In this study we used two subscales, the self and global domains. Each domain has seven items and scores can range from 7 to 42 within each domain, with higher scores indicating greater life satisfaction. The MSLSS has been shown to have adequate reliability and validity in students without disabilities (Gilman et al., 2000; Huebner, 1994; Huebner et al., 1998) and in students with cognitive disabilities (Brantley, Huebner, \& Nagle, 2002; McCullough \& Huebner, 2003). Cronbach's alpha values in this study were 0.91 and 0.86 for the global domain in students without disabilities and in students with cognitive disabilities, respectively. For the self domain, Cronbach's alpha values were 0.88 and 0.90 for students without and with disabilities, respectively.

\section{Missing data}

Within the data set, there was a small amount of missing data on a number of variables. The total percentage of missing data values was $1.1 \%$ for students with disabilities and $2.1 \%$ for students without disabilities. Because of the potential deleterious effects of not including all available data in the analysis process, we used the EM imputation algorithm using the PROC MI procedure within the SAS program (Graham, Cumsille, \& Elek-Fisk, 2003). In so doing, we used the totality of information within our data set to impute the missing data, and therefore maintained important characteristics of the data set, improving our ability to calculate unbiased and efficient parameter estimates (Graham et al., 2003). ${ }^{1}$ 


\section{Analytic procedures}

We used structural equation modeling (SEM) to examine our research questions. SEM allows researchers to flexibly and powerfully examine the relationships between observed and latent variables as well as test cross-group similarities and differences among multiple latent variables (Kline, 1998). SEM procedures involve the integration of measurement models (which specify the relationships among latent and observed variables) with structural models (which specify the relationship between latent factors). Specifically, the measurement equivalence of the constructs across groups can be assessed, and direct statistical comparisons of the similarities and differences in the means, variances, correlations, and regression relationships among the constructs can be examined (Little, 1997). Based on our research questions, we sequentially tested our hypothesized models in the following steps: (a) a test of the measurement model that specifies the relationship between manifest indicators (e.g., observed variables) and latent constructs (e.g., unobserved variables), (b) a test of the measurement equivalence in the measurement of these models across adolescents with and without disabilities (e.g., the equating of the loadings and intercepts of the observed variables across groups), (c) a test of the homogeneity of the variances and covariances of the latent constructs in adolescents with and without cognitive disabilities, (d) a test of the equivalence of the patterns of correlations of the latent constructs in adolescents with and without cognitive disabilities, (e) a test of the equivalence of the means of the latent constructs in adolescents with and without disabilities, and (f) tests of the structural models that specify the causal relationship between the latent constructs in youth with and without cognitive disabilities (Kline, 1998; Little, 1997).

In the measurement model there were nine latent constructs: autonomy (AUT), self-regulation (SREG), psychological empowerment (PSYE), selfrealization (SREA; the subdomains of the ASDA), agency thinking (CHSA), pathway thinking (CHSP; the subdomains of the CHS), optimism (LOT-R), locus of control (ANS-IE), and life satisfaction (LSAT). We chose to create latent constructs representing the subdomains of the ASDA and the CHS in our measurement model to further evaluate the relationships between these subdomains and the other positive psychology constructs. In our structural model, however, we created higher-order factors from these subdomains representing overall self-determination and hope (see below). For the latent constructs of autonomy, self-regulation, psychological empowerment, self-realization, optimism, and locus of control, domain-representative parcels were created to form three manifest indicators for each latent construct. ${ }^{2}$

Parceling is a technique commonly used with established measures such as these. A parcel can be defined as "an aggregate-level indicator comprised of the sum (or average) of two or more items, responses, or behaviors" (Little, Cunningham, Shahar, \& Widaman, 2002, p. 152). Parceling offers many advantages over item-level modeling, including greater parsimony, fewer chances for correlated residuals or dual loadings of indicators, and reductions in sampling error (Little et al., 2002). To create parcels for each of the afore-mentioned latent constructs, the item-to-construct balancing technique was utilized (see Little et al., 2002, for details). For the agency and pathways thinking construct, because only three items were associated with each construct the items were used as the indicators. For the life satisfaction construct, the total scores of the three scales assessing this domain (i.e., SWL, MSLSS-Self, and MSLSS-Global) were used as indicators (i.e., facet representative parcels; Little et al., 2002). Because of the variability in the scales of measurement across the constructs, each indicator was standardized to have a mean of zero and a standard deviation of 1.0 across the no disability and disability groups.

Additionally, in order to set the scale, instead of using traditional methods such as setting the latent variance to equal 1.0 , or setting one indicator to equal 1.0, we used a balancing technique (the effectscoding method; see Little, Slegers, \& Card, in press, for more information) which allowed us to set the scale by constraining the sum of the indicator's loadings to be equal to the number of indicators (i.e., sample LISREL syntax: CO LY $(1,1)=3-\operatorname{LY}(2,1)-$ $\mathrm{LY}(3,1))$. By using this technique, we were able to estimate each construct's latent variance in the disability and no disability group in a comparable, nonarbitrary metric (Little et al., in press), a procedure that cannot be preformed with the traditional methods mentioned above. Specifically this method:

maintains a construct scaling that is in a meaningful metric; namely, a given latent variable will be on the same scale as the average of all its manifest indicators... In line with the basic principles of aggregation, the average of a set of indicators would be a more accurate estimate of the population value than any one indicator arbitrarily chosen from the set (Little et al., in press, p. 10).

We used a similar procedure to define and set the scale of the intercepts such that the latent means could be estimated in both groups in a comparable and non-arbitrary metric and evaluated for differences across groups using nested-model chi-square tests. 
To test our hypothesized structural model for youth with and without cognitive disabilities, we created two higher-order constructs: self-determination, which was comprised of the first-order constructs, autonomy, self-regulation, psychological empowerment, and self-realization; and hope, which was comprised of the first-order constructs of agency and pathways thinking. We then tested the ability of self-determination, hope, optimism, and locus of control to predict life satisfaction in students with and without cognitive disabilities.

\section{Results}

As described in "Methods", using the SEM framework, we sequentially tested our hypothesized measurement and structural models based on our research questions. Here we present our findings as they relate to the (a) measurement models and (b) structural models.

\section{Measurement model}

Our first research question centered on whether the constructs we were attempting to measure were the same across the no disability and disability groups. Specifically, we were interested in whether strong metric invariance (i.e., invariance of the loadings and intercepts of the manifest indicators) could be established across the no disability and disability groups. To answer this question, we examined the measurement model using a two-group mean and covariances structures model. The initial, freely estimated, model demonstrated acceptable fit $\left(\chi^{2}(576, n=360)=993.25, p=<0.001\right.$, RMSEA $=$ $0.056, \mathrm{NNFI}=0.95, \mathrm{CFI}=0.96)$. Next, following standard procedures to evaluate measurement invariance, we equated the loadings and the intercepts (in sequential steps) and, as shown in Table I, found no significant changes in fit based on the RMSEA Model Test (i.e., does the RMSEA value of the nested model fall within the 90\% RMSEA confidence interval of the comparison model, Little, 1997; note too, that changes in the CFI were less than 0.01, see Cheung \& Rensvold, 2002). These tests indicate that the constructs included in the model (autonomy, self-regulation, psychological empowerment, self-realization, agency thinking, pathways thinking, optimism, locus of control, and life satisfaction) are invariant when measured across the no disability and disability groups, meaning the same constructs are being assessed in students with and without disabilities. The loading, intercept, residual, and squared multiple correlation values for each indicator, along with the variance for each latent construct in the strong metric invariant model, are presented in Table II.
We also evaluated the homogeneity of the variances and covariances of the latent constructs. The test revealed significant differences between youth with and without disabilities, as shown in Table I. However, follow-up tests demonstrated that the differences in variances were driving these significant findings (see Table II). Using procedures described by Little (1997), we tested the equivalence of the correlations among the constructs in students with and without disabilities. Invariance in the pattern of correlations was established, $\left(\Delta \chi^{2}\right.$ $(36, n=360)=38.31, p>0.05)$. The common correlations between the constructs for students with and without disabilities are presented in Table III.

We then evaluated the relationships between the latent means across the two groups. Specifically, we evaluated the latent means to determine if they were invariant across the no disability and disability groups and, as shown in Table I, they were not $\left(\Delta \chi^{2} \quad(9, \quad n=360)=51.16, \quad p<0.001\right)$. Further evaluation demonstrated significant differences in the latent means for self-regulation, psychological empowerment, agency thinking, and locus of control, with students without disabilities scoring more adaptively on each construct, as shown in Table IV.

\section{Structural models}

Our hypothesized structural model included two higher-order constructs of self-determination and hope, created from the lower-order constructs included in the measurement model. The structural model, with these higher order constructs included demonstrated acceptable model fit $\left(\chi^{2}\right.$ (636, $n=360)=1137.10, \quad p=<0.001, \quad$ RMSEA $=0.062$, $\mathrm{NNFI}=0.95, \mathrm{CFI}=0.96)$. Moreover, the loadings (beta weights) of the lower order constructs on the higher-order self-determination construct were equivalent across the no disability and disability groups $\left(\Delta \chi^{2} \quad(3, n=360)=1.39, p>0.25\right)$. The loading of each of the lower-order constructs on the higher-order self-determination construct is presented in Table V. As Table V shows, the selfregulation construct had a significantly lower loading on the higher-order self-determination construct than the other three lower-order constructs (autonomy, psychological empowerment, and selfrealization), although they were all significant. To identify and set the scale for the hope construct, we equated and fixed to 1.0 the regression paths from the lower-order constructs (agency and pathways) to the higher-order hope construct.

Because, we were interested in the degree to which the various constructs (self-determination, hope, optimism, and locus of control) predicted life satisfaction, we examined the regression weights for 
Table I. Fit indices for the nested sequence in the multiple group confirmatory factor analysis.

\begin{tabular}{|c|c|c|c|c|c|c|c|c|c|c|c|}
\hline Model & $\chi^{2}$ & $d f$ & $p$ & $\Delta \chi^{2}$ & $\Delta d f$ & $p$ & RMSEA & RMSEA $90 \%$ CI & NNFI & CFI & Constraint tenable \\
\hline Configural invariance & 993.25 & 576 & $<0.001$ & - & - & - & 0.056 & $0.049-0.063$ & 0.95 & 0.96 & - \\
\hline Loading invariance $^{1}$ & 1013.47 & 594 & $<0.001$ & - & - & - & 0.056 & $0.049-0.063$ & 0.96 & 0.96 & Yes \\
\hline Intercept invariance $^{1}$ & 1047.10 & 612 & $<0.001$ & - & - & - & 0.056 & $0.049-0.063$ & 0.96 & 0.96 & Yes \\
\hline Homogenity of variances ${ }^{2}$ & 1115.92 & 621 & $<0.001$ & 68.82 & 9 & $<0.001$ & 0.058 & $0.051-0.065$ & 0.95 & 0.96 & No \\
\hline Homogeneity of variances/covariances ${ }^{2}$ & 1131.35 & 657 & $<0.001$ & 84.25 & 45 & $<0.001$ & 0.057 & $0.051-0.064$ & 0.95 & 0.96 & No \\
\hline Equality of correlations ${ }^{2}$ & 1085.41 & 648 & $<0.001$ & 38.31 & 36 & $>0.05$ & 0.055 & $0.048-0.062$ & 0.96 & 0.96 & Yes \\
\hline Latent mean invariance $^{2}$ & 1098.26 & 621 & $<0.001$ & 51.16 & 9 & $<0.001$ & 0.059 & $0.052-0.065$ & 0.95 & 0.96 & No \\
\hline
\end{tabular}

Note: Each nested model contains its constraints, plus the constraints of all previous, tenable models.

${ }^{1}$ Evaluated with the RMSEA model test.

${ }^{2}$ Evaluated with the $\chi^{2}$ difference test. 
Table II. Loading and intercept values, residuals, and $R^{2}$ values for each indicator, and the estimated latent variance from the strong metric invariance model.

\begin{tabular}{|c|c|c|c|c|c|c|c|}
\hline \multirow[b]{2}{*}{ Indicator } & \multicolumn{2}{|c|}{ Equated estimates } & \multirow{2}{*}{$\begin{array}{l}\text { Standardized } \\
\text { Loading }^{\mathrm{a}}\end{array}$} & \multicolumn{2}{|c|}{ No disability } & \multicolumn{2}{|c|}{ Disability } \\
\hline & Loading (SE) & Intercept (SE) & & Theta & $R^{2}$ & Theta & $R^{2}$ \\
\hline \multicolumn{8}{|c|}{ Autonomy $($ AUT $)$ : Estimated latent variance $($ No disability $=0.64 ;$ Disability $=1.22)$} \\
\hline Parcel 1 & $1.00(0.03)$ & $0.00(0.02)$ & 0.87 & 0.24 & 0.72 & 0.26 & 0.83 \\
\hline Parcel 2 & $1.01(0.03)$ & $0.00(0.02)$ & 0.88 & 0.24 & 0.73 & 0.22 & 0.85 \\
\hline Parcel 3 & $0.99(0.03)$ & $0.00(0.02)$ & 0.86 & 0.26 & 0.71 & 0.29 & 0.81 \\
\hline \multicolumn{8}{|c|}{ Self-regulation $($ SREG $)$ : Estimated latent variance $($ No disability $=0.49 ;$ Disability $=0.36)$} \\
\hline Parcel 1 & $0.97(0.06)$ & $0.00(0.03)$ & 0.67 & 0.52 & 0.48 & 0.65 & 0.35 \\
\hline Parcel 2 & $1.05(0.06)$ & $0.00(0.03)$ & 0.73 & 0.50 & 0.53 & 0.38 & 0.52 \\
\hline Parcel 3 & $0.98(0.06)$ & $0.00(0.03)$ & 0.67 & 0.57 & 0.46 & 0.46 & 0.44 \\
\hline \multicolumn{8}{|c|}{ Psychological empowerment (PSYE): Estimated latent variance $($ No disability $=0.51$; Disability $=0.79)$} \\
\hline Parcel 1 & $0.96(0.04)$ & $0.00(0.03)$ & 0.73 & 0.43 & 0.53 & 0.58 & 0.57 \\
\hline Parcel 2 & $1.09(0.04)$ & $0.00(0.03)$ & 0.83 & 0.30 & 0.68 & 0.34 & 0.74 \\
\hline Parcel 3 & $0.94(0.04)$ & $0.00(0.03)$ & 0.72 & 0.46 & 0.50 & 0.60 & 0.55 \\
\hline \multicolumn{8}{|c|}{ Self-realization $($ SREA $)$ : Estimated latent variance $($ No disability $=0.42 ;$ Disability $=0.17)$} \\
\hline Parcel 1 & $0.88(0.07)$ & $0.01(0.04)$ & 0.53 & 0.68 & 0.32 & 0.85 & 0.13 \\
\hline Parcel 2 & $0.87(0.07)$ & $0.00(0.03)$ & 0.53 & 0.71 & 0.31 & 0.77 & 0.14 \\
\hline Parcel 3 & $1.25(0.06)$ & $-0.02(0.03)$ & 0.76 & 0.35 & 0.65 & 0.73 & 0.26 \\
\hline \multicolumn{8}{|c|}{ Hope-Agency $(\mathrm{CHSA})$ : Estimated latent variance $($ No disability $=0.54 ;$ Disability $=0.49)$} \\
\hline CHS Item 1 & $1.04(0.04)$ & $0.00(0.03)$ & 0.77 & 0.36 & 0.63 & 0.63 & 0.47 \\
\hline CHS Item 3 & $1.05(0.04)$ & $0.01(0.03)$ & 0.78 & 0.36 & 0.63 & 0.54 & 0.51 \\
\hline CHS Item 5 & $0.90(0.04)$ & $0.00(0.03)$ & 0.66 & 0.49 & 0.47 & 0.85 & 0.32 \\
\hline \multicolumn{8}{|c|}{ Hope - Pathways $(\mathrm{CHSP})$ : Estimated latent variance $($ No disability $=0.61 ;$ Disability $=0.75)$} \\
\hline CHS Item 2 & $0.92(0.04)$ & $0.01(0.03)$ & 0.73 & 0.41 & 0.55 & 0.73 & 0.46 \\
\hline CHS Item 4 & $1.05(0.04)$ & $-0.01(0.02)$ & 0.84 & 0.28 & 0.71 & 0.36 & 0.70 \\
\hline CHS Item 6 & $1.04(0.04)$ & $0.00(0.03)$ & 0.83 & 0.32 & 0.67 & 0.28 & 0.74 \\
\hline \multicolumn{8}{|c|}{ Optimism $($ LOT-R): Estimated latent variance $($ No disability $=0.58 ;$ Disability $=0.76)$} \\
\hline Parcel 1 & $1.09(0.04)$ & $0.00(0.03)$ & 0.85 & 0.27 & 0.71 & 0.29 & 0.76 \\
\hline Parcel 2 & $1.01(0.04)$ & $0.00(0.03)$ & 0.79 & 0.36 & 0.62 & 0.46 & 0.62 \\
\hline Parcel 3 & $0.90(0.04)$ & $0.00(0.03)$ & 0.69 & 0.47 & 0.49 & 0.71 & 0.45 \\
\hline \multicolumn{8}{|c|}{ Locus of control (ANS-IE): Estimated latent variance $($ No disability $=0.46$; Disability $=0.45)$} \\
\hline Parcel 1 & $0.88(0.06)$ & $0.00(0.03)$ & 0.60 & 0.61 & 0.37 & 0.75 & 0.32 \\
\hline Parcel 2 & $1.16(0.05)$ & $0.00(0.03)$ & 0.80 & 0.36 & 0.64 & 0.34 & 0.62 \\
\hline Parcel 3 & $0.96(0.05)$ & $0.00(0.03)$ & 0.66 & 0.56 & 0.44 & 0.58 & 0.43 \\
\hline \multicolumn{8}{|c|}{ Life satisfaction $($ LSAT): Estimated latent variance $($ No disability $=0.65$; Disability $=0.62)$} \\
\hline SWL Total & $1.10(0.03)$ & $0.00(0.02)$ & 0.88 & 0.25 & 0.75 & 0.15 & 0.83 \\
\hline MSLSS-S & $0.80(0.04)$ & $0.00(0.03)$ & 0.65 & 0.55 & 0.43 & 0.72 & 0.36 \\
\hline MSLSS-G & $1.10(0.03)$ & $0.00(0.02)$ & 0.88 & 0.21 & 0.79 & 0.32 & 0.70 \\
\hline
\end{tabular}


Table III. Correlations between latent constructs for no disability and disability groups.

\begin{tabular}{|c|c|c|c|c|c|c|c|c|c|}
\hline & AUT & SREG & PSYE & SREA & CHSA & CHSP & LOTR & ANS-IE & LSAT \\
\hline AUT & 1.00 & & & & & & & & \\
\hline SREG & 0.23 & 1.00 & & & & & & & \\
\hline PSYE & 0.41 & 0.27 & 1.00 & & & & & & \\
\hline SREA & 0.33 & 0.14 & 0.77 & 1.00 & & & & & \\
\hline CHSA & 0.47 & 0.13 & 0.40 & 0.50 & 1.00 & & & & \\
\hline CHSP & 0.49 & 0.15 & 0.33 & 0.44 & 0.89 & 1.00 & & & \\
\hline LOTR & 0.40 & 0.12 & 0.44 & 0.48 & 0.57 & 0.50 & 1.00 & & \\
\hline ANS-IE & -0.28 & -0.29 & -0.57 & -0.48 & -0.48 & -0.44 & -0.57 & 1.00 & \\
\hline LSAT & 0.27 & 0.10 & 0.34 & 0.55 & 0.71 & 0.51 & 0.64 & -0.45 & 1.00 \\
\hline
\end{tabular}

Note: $\quad$ AUT = Autonomy; SREG = Self-regulation; PSYE = Psychological empowerment; SREA = Self-realization; CHSA=Agency thinking; $\mathrm{CHSP}=$ Pathways thinking; LOTR $=$ Optimism; ANS $=$ Locus of control; LSAT $=$ Life satisfaction.

Table IV. Results of nested Chi-square tests for latent mean level differences.

\begin{tabular}{|c|c|c|c|c|c|c|c|c|c|}
\hline Constructs & $\begin{array}{c}\text { Latent } \\
\text { mean No } \\
\text { disability }\end{array}$ & $\begin{array}{l}\text { Latent } \\
\text { mean } \\
\text { Disability }\end{array}$ & $\chi^{2}$ & $d f$ & $p$ & $\Delta \chi^{2}$ & $\Delta d f$ & $p$ & $\begin{array}{l}\text { Equivalent } \\
\text { across } \\
\text { groups }\end{array}$ \\
\hline Intercept invariance (Baseline model) & - & - & 1047.10 & 612 & $<0.001$ & - & - & - & \\
\hline Autonomy & -0.02 & 0.09 & 1047.80 & 613 & $<0.001$ & 0.70 & 1 & $>0.05$ & Yes \\
\hline Self-regulation & 0.10 & -0.36 & 1067.74 & 613 & $<0.001$ & 20.64 & 1 & $<0.001$ & No \\
\hline Psychological empowerment & 0.07 & -0.26 & 1053.83 & 613 & $<0.001$ & 6.73 & 1 & $<0.01$ & No \\
\hline Self-realization & 0.03 & -0.11 & 1049.46 & 613 & $<0.001$ & 2.36 & 1 & $>0.05$ & Yes \\
\hline Hope-Agency & 0.08 & -0.32 & 1059.64 & 613 & $<0.001$ & 12.54 & 1 & $<0.001$ & No \\
\hline Hope-Pathways & 0.00 & 0.01 & 1047.11 & 613 & $<0.001$ & 0.01 & 1 & $>0.05$ & Yes \\
\hline Optimism & 0.02 & -0.08 & 1047.92 & 613 & $<0.001$ & 0.82 & 1 & $>0.05$ & Yes \\
\hline Locus of control & -0.09 & 0.33 & 1062.71 & 613 & $<0.001$ & 15.61 & 1 & $<0.001$ & No \\
\hline Life satisfaction & 0.01 & -0.01 & 1047.11 & 613 & $<0.001$ & 0.01 & 1 & $>0.05$ & Yes \\
\hline
\end{tabular}

Note: Indicators standardized to have a mean of zero and standard deviation of 1.0 across the disability and no disability groups.

Table V. Loadings of the lower-order constructs on the higherorder self-determination construct.

\begin{tabular}{lcrl}
\hline Indicator & $B e t a(\mathrm{SE})$ & $z$-score & $p$-value \\
\hline Autonomy & $0.98(0.10)$ & 9.50 & $<0.05$ \\
Self-regulation & $0.45(0.10)$ & 4.45 & $<0.05$ \\
Psychological empowerment & $1.43(0.10)$ & 13.69 & $<0.05$ \\
Self-realization & $1.14(0.11)$ & 10.69 & $<0.05$ \\
\hline
\end{tabular}

each of these relationships. First, we sequentially removed non-significant regression paths from the model. Locus of control did not predict life satisfaction in either group (no disability, $\beta=-0.05$, $z=-0.42, p>0.05$; disability, $\beta=0.18, z=0.78$, $p>0.05)$, and was thus dropped from further analysis. Similarly, self-determination did not predict life satisfaction in either group (no disability, $\beta=0.20, z=1.12, \quad p>0.05$; disability, $\beta=0.26$, $z=1.08, p>0.05)$. At each step of removing nonsignificant paths, optimism and hope remained significant predictors of life satisfaction. We tested the difference in the effects of optimism and hope on life satisfaction for students with and without disabilities and their effects did not significantly differ $\left(\Delta \chi^{2}(2, n=360)=0.58, p>0.50\right)$. After evaluating the regression paths, we moved on to evaluate the equivalence of the variances and correlations in the structural model. As in the measurement model, there were significant differences in the variances of the constructs between the groups $\left(\Delta \chi^{2}(11, n=360)=42.69, p<0.001\right)$, but not in the correlations between the constructs $\left(\Delta \chi^{2}(6, n=360)=10.88, p>0.05\right)$. The final structural model is presented in Figure 1.

\section{Discussion}

The purpose of this study was to explore the interrelationships between positive psychology constructs in students with and without cognitive disabilities. Using the flexible SEM framework, we were able to evaluate a number of questions related to the nature of these interrelationships. In exploring the implications of our findings, the discussion section will be divided into three sections: limitations of the study, summary of the findings, and implications for future research.

\section{Limitations of the study}

One of the primary limitations to this study was the relatively small sample of adolescents with cognitive 


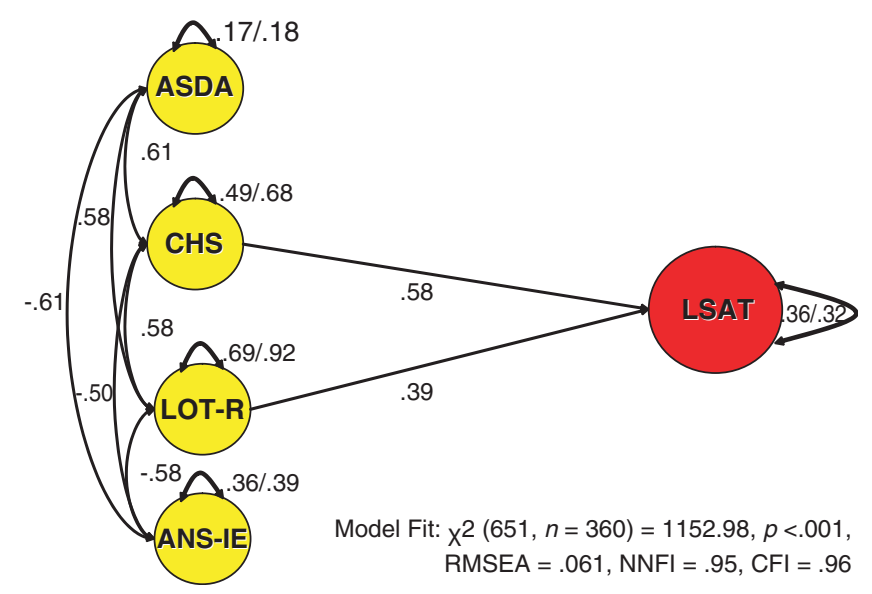

Figure 1. Final structural model for the no disability/disability groups. ASDA=Adolescent Self-Determination Assessment; $\mathrm{CHS}=$ Children's Hope Scale; LOT-R =Life Orientation Test-Revised; ANS-IE=Nowicki-Strickland Internal-External Scales; LSAT $=$ Life Satisfaction .

disabilities $(n=75)$. Although there are no set criteria for determining the appropriate sample size for SEM, generally, it is preferable to have a larger sample size, particularly given the complexity of our model and the exploratory nature of our study (Muthén \& Muthén, 2002). Further, because of the limited demographic information made available to the authors, we were unable to undertake any analyses related to differences between students with learning disabilities and mild/moderate mental retardation, as the only information provided was that students were receiving special education services under the label of learning disabilities or mild/moderate mental retardation without the exact label being specified for a given student, or differences based on gender or race/ ethnicity. Further, several of the instruments used in our study had never been evaluated in students with or students without cognitive disabilities. The low reliability for the LOT-R in students with cognitive disabilities reflects the need to further evaluate its use in adolescents with cognitive disabilities. Finally, the low correlations between the subscale latent constructs of the ASDA and the low loading of the self-regulation subscale on the higher order selfdetermination construct suggests that future research is needed to evaluate the measurement of selfdetermination using the ASDA in adolescents with and without disabilities, particularly as past research, with The Arc's Self-Determination Scale, has suggested that the subscales tend to be more strongly correlated and that the self-regulation subscale is a important component of self-determination that is highly predictive of positive outcomes, including quality of life (Wehmeyer, 1996b; Wehmeyer \& Kelchner, 1995; Wehmeyer \& Schwartz, 1998).

Anecdotally, the self-regulation subscale of the ASDA had a large amount of missing data compared to the other scales and subscales, perhaps because the subscale questions required students to write a response that completed a means-ends problem solving story (Platt \& Spivack, 1989), whereas the rest of the questions on the ASDA and the other scales simply involved selecting a number on a rating scale. Although the missing data was imputed, it is possible that the nature of the questions may have lead to less overall reliability in the adolescent's responses on the self-regulation subscale. Future research is needed to examine the use of the selfregulation subscale of the ASDA in adolescents with and without cognitive disabilities. Strategies to promote the reliable completion of the means-ends problem solving questions by adolescents with and without cognitive disabilities in group administration situations may be critical to this endeavor. Thus, the findings of this study, particularly as they relate to self-determination, must be interpreted with caution.

Despite these limitations, by using the flexible SEM framework, which controls for measurement error and allows us to evaluate our data on multiple levels, we were able to begin the process of exploring the interrelationships between self-determination, hope, optimism, locus of control, and life satisfaction, and, as we discuss in the following sections, provide direction for future research and practice in the positive psychology and disability fields.

\section{Summary of the findings}

Invariance of the loadings and intercepts. Our first step was to evaluate the construct comparability, or measurement equivalence, of the nine latent constructs we evaluated (autonomy, self-regulation, psychological empowerment, self-realization, agency thinking, pathways thinking, optimism, locus of control, and life satisfaction) in adolescents with and without disabilities. For many of these 
constructs, this represented their first evaluation in students with cognitive disabilities (agency thinking, pathways thinking, and optimism) or in students without disabilities (autonomy, self-regulation, psychological empowerment, and self-realization). Ensuring that the loadings and intercepts of each of the latent constructs were equivalent provided a basis to assume that, because the constructs are defined in the same operational manner in each group, the construct's variance, correlational, and mean-level differences can be compared meaningfully and with quantitative precision (Little, 1997). Finding measurement equivalence was essential to further evaluating the interrelations among these constructs, and provides a basis for future research comparing and assessing these constructs in adolescents with and without cognitive disabilities.

Pattern of interrelationships. After establishing measurement equivalence we were able to evaluate the equivalence of the construct's variances, covariances, and correlations across the two groups. Through these procedures, we were able to establish that there were differences across the groups in the variances of the constructs. This finding provides important information to consider in future research within other analytic frameworks (i.e., traditional ANOVA procedures which assume homogeneity of variance). However, in terms of the pattern of correlations between the latent constructs, we found there was equivalence across adolescents with and without disabilities, indicating there were no significant differences in the pattern of interrelationships among the latent constructs. Further, as shown in Table III, the pattern of correlations among the nine latent constructs that comprised the measurement model suggest that there are commonalities among the constructs but, given the magnitude of the correlations, each of the constructs was distinct in what it was measuring. However, as research moves forward, it will be important to further consider the nature of these commonalities. For example, the autonomy subscale of the ASDA was more strongly correlated with the agency and pathways subscales of the CHS than the other subscales on the ASDA. Further, the self-regulation subscale of the ASDA had relatively low correlations with all of the other latent constructs, including the other subscales of the ASDA (although readers should note the previous discussion pertaining to the reliability of the scores in the self-regulation section). Therefore, future research is necessary to evaluate the relationships between the subdomains of self-determination and hope and, more generally, to examine strategies to reliably measure self-regulated behavior in adolescents with and without cognitive disabilities.
Mean level differences. As shown in Table IV, there were significant latent mean differences on a number of the constructs (self-regulation, psychological empowerment, agency thinking, and locus of control). The direction of these findings, less adaptive scores for adolescents with cognitive disabilities, supports past research that suggests students with cognitive disabilities tend to: have fewer opportunities to learn the skills necessary to self-regulate their learning and behavior (Mithaug, Mithaug, Agran, Martin, \& Wehmeyer, 2003; Wehmeyer, Yeager, Bolding, Agran, \& Hughes, 2003; Whitman, 1990), feel psychologically disempowered rather than empowered (Wehmeyer, 1994b), and have fewer opportunities to exert control over their environment (Wehmeyer \& Kelchner, 1996). The mean level difference in agency thinking suggests that adolescents with cognitive disabilities also may not perceive themselves as being capable of using pathways thinking to achieve their goals, even though the lack of mean level difference in pathways thinking suggests that adolescents with cognitive disabilities do not view their ability to generate workable strategies to achieve their goals differently than students without cognitive disabilities. These differences in agency and pathways thinking in students with and without cognitive disabilities needs to be further evaluated, particularly as they relate to the mean-level differences on the self-regulation subscale of the ASDA.

In terms of life satisfaction, there is a small research base that suggests that students with and without disabilities (Brantley et al., 2002; Griffin, 2000; McCullough \& Huebner, 2003) do not significantly differ in their global life satisfaction, supporting our findings in this study, but that they do differ on particular domains of life satisfaction (not assessed in this study), including satisfaction with their friends. Thus, further research is needed to replicate and further evaluate mean-level differences in global and domain-specific aspects of life satisfaction, as well as differences in autonomy, selfrealization, and optimism in students with and without cognitive disabilities.

Prediction of life satisfaction. Finally, we were able to move to the level of analyzing the predictive relationships between the latent constructs in our structural models. We were able to create higher-order factors from lower-order constructs (i.e., self-determination and hope), creating hierarchies of prediction, evaluating both the measurement equivalence of the subdomains of self-determination and hope as well as the contribution of the subdomains of selfdetermination to the higher-order self-determination construct. Specifically, we found that the loadings of 
the four subscales of the ASDA were equivalent across the two groups. However, the self-regulation subscale contributed much less to the higher order self-determination construct than the other three subscales, see Table V. Future research is needed to evaluate this finding, particularly given the strong body of research supporting the contribution of the self-regulation subdomain to The Arc's SelfDetermination Scale (Wehmeyer, 1996b; Wehmeyer \& Kelchner, 1995), and the possibility that, in this study, there were issues with the reliably of adolescents responses on the self-regulation subscale of the ASDA.

Additionally, we were able to test the ability of selfdetermination, hope, optimism, and locus of control to predict life satisfaction. Our findings revealed that locus of control and self-determination were not significant predictors of life satisfaction in students with and without cognitive disabilities, although selfdetermination was a stronger predictor than locus of control and approached significance. Hope and optimism, however, did significantly predict life satisfaction, at an equivalent level in students with and without disabilities. This finding supports the importance of hope and optimism in developing interventions to enhance life satisfaction in students with and without disabilities. Given the preliminary nature of this study, further research is needed to examine the role of each of these constructs. The role of self-determination needs to be investigated further, given that a large body of research suggests that self-determination contributes to positive outcomes for students with disabilities (Wehmeyer \& Palmer, 2003; Wehmeyer \& Schwartz, 1997, 1998). As there may have been issues with the measurement of self-determination in this study, that problem may account for failure of self-determination to significantly predict life satisfaction. Additionally, future research is needed to more specifically examine the relationship between locus of control and life satisfaction, particularly given recent research (Ash \& Huebner, 2001) suggesting that, rather than predicting life satisfaction, locus of control may act as a mediator between negative life events and chronic stressors and life satisfaction in adolescents, relationships we were unable to explore in this study.

Finally, we were able to evaluate the variances and correlations of the constructs in the structural model for equivalence across groups. As in the measurement model, we found there were significant differences in the construct's latent variances across the two groups, but not in the pattern of correlations. When looking at the correlations (see Figure 1), it is clear that self-determination, hope, optimism, and locus of control are significantly related. This suggests the need for future research that further assesses the commonalities, as well as the distinguishing features, of each construct.

\section{Implications for future research}

The purpose of this study was to bring together several lines of research that focus on promoting positive outcomes in adolescents with and without cognitive disabilities, exploring the associations between several constructs associated with the positive psychology movement. As discussed above, the use of SEM allowed us to flexibly examine the interrelationships of these constructs in adolescents with and without cognitive disabilities at multiple levels, providing direction for future research in this area. Specifically, it will be important to further evaluate the relationships of self-determination with other positive psychology constructs. Given the significant correlations between self-determination, hope, optimism, and locus of control, it will be important to evaluate how these constructs converge and diverge, and how they work together to promote optimal functioning (Snyder \& Lopez, 2002). However, and perhaps more importantly, this research provides an impetus to unify diverse lines of research and work to better understand the factors that contribute to positive outcomes for adolescents with and without cognitive disabilities.

\section{Notes}

1. Supplemental analyses were also conducted on complete cases. A similar pattern of results was found in the analysis of complete cases and in the analysis of the imputed data set. Contact the authors for more detailed information on these supplemental analyses.

2. To receive information on the means, standard deviations, and correlations among the manifest indicators please contact the authors.

\section{References}

Ash, C., \& Huebner, E. (2001). Environmental events and life satisfaction reports of adolescents: A test of cognitive mediation. School Psychology International, 22, 320-336.

Brantley, A., Huebner, E. S., \& Nagle, R. J. (2002). Multidimensional life satisfaction reports of adolescents with mild mental disabilities. Mental Retardation, 40, 321-329.

Carver, C. S., \& Scheier, M. F. (1998). On the self-regulation of behavior. New York: Cambridge University Press.

Carver, C. S., \& Scheier, M. F. (2002). Optimism. In C. R. Snyder \& S. J. Lopez (Eds), Handbook of positive psychology (pp. 231-243). London: Oxford University Press.

Carver, C. S., \& Scheier, M. F. (2003). Optimism. In C. R. Snyder \& S. J. Lopez (Eds), Positive psychological assessment: A handbook of models and measures (pp. 75-89). Washington, DC: American Psychological Association. 
Chafouleas, S. M., \& Bray, M. A. (2004). Introducing positive psychology: Finding a place within school psychology. Psychology in the Schools, 41, 1-5.

Cheung, G. W., \& Rensvold, R. B. (2002). Evaluating goodnessof-fit indexes for testing measurement invariance. Structural Equation Modeling, 9, 233-255.

Clark, E., Olympia, D. E., Jensen, J., Heathfield, L. T., \& Jenson, W. R. (2004). Striving for autonomy in a contingency-governed world: Another challenge for individuals with developmental disabilities. Psychology in the Schools, 41, 143-153.

Dew, T., \& Huebner, E. (1994). Adolescent's perceived quality of life: An exploratory investigation. Fournal of School Psychology, 32, 185-199.

Diener, E., Emmons, R. A., Larson, R. W., \& Griffin, S. (1985). The Satisfaction With Life scale. Fournal of Personality Assessment, 49, 71-75.

Diener, E., Lucas, R. E., \& Oishi, S. (2002). Subjective wellbeing: The science of happiness and life satisfaction. In C. R. Snyder \& S. J. Lopez (Eds), Handbook of positive psychology (pp. 463-473). London: Oxford University Press.

Dudley-Marling, C. C., Snider, V., \& Tarver, S. G. (1982). Locus of control and learning disabilities: A review and discussion. Perceptual and Motor Skills, 54, 503-514.

Edwards, L. M. (2004). Factors contributing to subjective wellbeing in Mexican-American of adolescents. Unpublished doctoral dissertation. University of Kansas: Lawrence.

Fournier, G., \& Jeanrie, C. (2003). Locus of control: Back to basics. In C. R. Snyder \& S. J. Lopez (Eds), Positive psychological assessment: A handbook of models and measures (pp. 139-154). Washington, DC: American Psychological Association.

Gilman, R. C., Huebner, E. S., \& Laughlin, J. E. (2000). A first study of the Multidimensional Students' Life Satisfaction Scale with adolescents. Social Indicators Research, 52, 135-160.

Graham, J. W., Cumsille, P. E., \& Elek-Fisk, E. (2003). Methods for handling missing data. In J. A. Schinka \& W. F. Velicer (Eds), Research methods in psychology (Vol. 2, pp. 87-114). New York: John Wiley \& Sons.

Grant, G., Ramcharan, P., \& Goward, P. (2003). Resilience, family care, and people with intellectual disabilities. In L. M. Glidden (Ed.), International review of research in mental retardation (Vol. 26, pp. 135-173). San Diego, CA: Academic Press.

Griffin, M. D. (2000). Multidimensional life satisfaction reports of middle school students with serious emotional disturbance. Fournal of Psychoeducational Assessment, 18, 111-124.

Hall, C. W., Spruill, K. L., \& Webster, R. E. (2002). Motivational and attitudinal factors in college students with and without learning disabilities. Learning Disability Quarterly, $25,79-86$.

Huebner, E. S. (1991). Correlates of life satisfaction in children. School Psychology Quarterly, 6, 103-111.

Huebner, E. S. (1994). Preliminary development and validation of a multidimensional life satisfaction scale for children. Psychological Assessment, 6, 149-158.

Huebner, E. S. (2004). Research on assessment of life satisfaction of children and adolescents. Social Indicators Research, 66, 3-33.

Huebner, E. S., \& Alderman, G. L. (1993). Convergent and discriminant validation of a children's life satisfaction scale: Its relationship to self- and teacher-reported psychological problems and school functioning. Social Indicators Research, $30,71-82$.

Huebner, E. S., Ash, C., \& Laughlin, J. E. (2001). Life experiences, locus of control, and school satisfaction in adolescence. Social Indicators Research, 55, 167-183.
Huebner, E. S., Laughlin, J. E., Ash, C., \& Gilman, R. (1998). Further validation of the Multidimensional Students' Life Satisfaction Scale. Fournal of Psychoeducational Assessment, 16, 118-134.

Huebner, E. S., \& McCullough, G. (2000). Correlates of school satisfaction among adolescents. Fournal of Educational Research, 93, 331-335.

Huebner, E. S., Suldo, S. M., Smith, L. C., \& McKnight, C. G. (2004). Life satisfaction in children and youth: Empirical foundations and implications for school psychologists. Psychology in the Schools, 41, 81-93.

Hunter, J. P., \& Csikszentmihalyi, M. (2003). The positive psychology of interested adolescents. Fournal of Youth and Adolescence, 32, 27-35.

Judge, T. A. (2003, October). Positive psychology at work. Paper presented at the 2003 International Positive Psychology Summit, Washington, DC.

Kline, R. B. (1998). Principles and practice of structural equation modeling. New York: Guilford.

Larson, R. W. (2000). Toward a psychology of positive youth development. American Psychologist, 55, 170-183.

Little, T. D. (1997). Mean and covariance structures (MACS) analyses of cross-cultural data: Practical and theoretical issues. Multivariate Behavioral Research, 32, 53-76.

Little, T. D., Cunningham, W. A., Shahar, G., \& Widaman, K. F. (2002). To parcel or not to parcel: Exploring the question, weighing the merits. Structural Equation Modeling, 9, 151-173.

Little, T. D., Slegers, D. W., \& Card, N. A. (in press). An alternative method of identifying and scaling latent variables in SEM and MACS models. Structural Equation Modeling.

Lopez, S. J., Snyder, C. R., \& Teramoto-Pedrotti, J. (2003). Hope: Many definitions, many measures. In S. J. Lopez \& C. R. Snyder (Eds), Positive psychological assessment: $A$ handbook of models and measures (pp. 91-107). Washington, DC: American Psychological Association.

McCullough, G. C., \& Huebner, E. S. (2003). Life satisfaction reports of adolescents with learning disabilities and normally achieving adolescents. Fournal of Psychoeducational Assessment, $21,311-324$.

McKnight, C. G., Huebner, E. S., \& Suldo, S. (2002). Relationships among stressful life events, temperament, problem behavior, and global life satisfaction in adolescents. Psychology in the Schools, 39, 677-687.

Meredith, W. (1993). Measurement invariance, factor analysis and factorial invariance. Psychometrika, 58, 525-543.

Mithaug, D. E., Mithaug, D. K., Agran, M., Martin, J. E., \& Wehmeyer, M. L. (2003). Self-determined learning theory: Construction, verification, and evaluation. Mahwah, NJ: Lawrence Erlbaum Associates.

Muthén, L. K., \& Muthén, B. O. (2002). How to use a Monte Carlo study to decide on sample size and determine power. Structural Equation Modeling, 9, 599-620.

Nowicki, S., \& Duke, M. P. (1974). A locus of control scale for college as well as noncollege adults. Fournal of Personality Assessment, 38, 136-137.

Nowicki, S., \& Strickland, B. R. (1973). A locus of control scale for children. Fournal of Consulting and Clinical Psychology, 40, 148-154.

Pajares, F. (2001). Toward a positive psychology of academic motivation. Fournal of Educational Research, 95, 27-35.

Pavot, W. G., Diener, E., Colvin, C. R., \& Sandvik, E. (1991). Further validation of the satisfaction with life scale: Evidence for the cross-method convergence of well-being measures. fournal of Personality Assessment, 57, 149-161.

Platt, J., \& Spivack, G. (1989). The MEPS procedure manual. Philadelphia: Department of Mental Health Sciences, Hahnemann University. 
Rich, G. J. (2003). The positive psychology of youth and adolescence. Fournal of Youth and Adolescence, 32, $1-3$

Roberts, M. C., Brown, K. J., Johnson, R. J., \& Reinke, J. (2002). Positive psychology for children: Development, prevention, and promotion. In C. R. Snyder \& S. J. Lopez (Eds), Handbook of positive psychology (pp. 663-675). London: Oxford University Press.

Rotter, J. B. (1966). Generalized expectancies for internal versus external control of reinforcement. Psychological Monographs, 80, 244-248.

Schalock, R. L. (2004). The emerging disability paradigm and its implications for policy and practice. Fournal of Disability Policy Studies, 14, 204-215.

Scheier, M. F., \& Carver, C. S. (1992). Effects of optimism on psychological and physical well-being: Theoretical overview and empirical update. Cognitive Therapy and Research, 16, 201-228.

Scheier, M. F., Carver, C. S., \& Bridges, M. W. (1994). Distinguishing optimism from neuroticism (and trait anxiety, self-mastery, and self-esteem): A reevaluation of the life orientation test. Fournal of Personality and Social Psychology, 67, 1063-1078.

Scheier, M. F., Weintraub, J. K., \& Carver, C. S. (1986). Coping with stress: Divergent strategies of optimists and pessimists. Fournal of Personality and Social Psychology, 51, $1257-1264$.

Seligman, M. E. P. (1998). Building human strength: Psychology's forgotten mission. APA Monitor, 29, 2.

Seligman, M. E. P. (1999). The president's address. American Psychologist, 54, 559-562.

Seligman, M. E. P., \& Csikszentmihalyi, M. (2000). Positive psychology: An introduction. American Psychologist, $55,5-14$

Snyder, C. R. (1994). The psychology of hope: You can get there from here. New York: Free Press.

Snyder, C. R., Harris, C., Anderson, J. R., Holleran, S. A., Irving, L. M., Sigmon, S. T., et al. (1991). The will and the ways: Development and validation of an individual-differences measure of hope. Fournal of Personality and Social Psychology, 60, 570-585.

Snyder, C. R., Hoza, B., Pelham, W. E., Rapoff, M., Ware, L., Danovsky, M., et al. (1997). The development and validation of the Children's Hope scale. Fournal of Pediatric Psychology, 22, 399-421.

Snyder, C. R., \& Lopez, S. J. (2002). The future of positive psychology: A declaration of independence. In C. R. Snyder \& S. J. Lopez (Eds), Handbook of positive psychology (pp. 751-767). London: Oxford University Press.

Snyder, C. R., Rand, K. L., \& Sigmon, D. R. (2002). Hope theory: A member of the positive psychology family. In C. R. Snyder \& S. J. Lopez (Eds), Handbook of positive psychology (pp. 257-276). London: Oxford University Press.

Snyder, C. R., Shorey, H. S., Cheavens, J., Pulvers, K. M., Adams, V. H. III, \& Wiklund, C. (2002). Hope and academic success in college. Fournal of Educational Psychology, 94, $820-826$.

Suldo, S. M., \& Huebner, E. S. (2004a). Does life satisfaction moderate the effects of stressful life events on psychopathological behavior during adolescence? School Psychology Quarterly, 19, 93-105.

Suldo, S. M., \& Huebner, E. S. (2004b). The role of life satisfaction in the relationship between authoritative parenting dimensions and adolescent problem behavior. Social Indicators Research, 66, 165-195.
Thomas, A., \& Pashley, B. (1982). Effects of classroom training on LD students' task persistence and attributions. Learning Disability Quarterly, 5, 133-144.

Wehmeyer, M. L. (1993a). Factor structure and construct validity of a locus of control scale with individuals with mental retardation. Educational and Psychological Measurement, 53, $1055-1066$.

Wehmeyer, M. L. (1993b). Gender differences in locus of control scores for students with learning disabilities. Perceptual and Motor Skills, 77, 359-366.

Wehmeyer, M. L. (1994a). Employment status and perceptions of control of adults with cognitive and developmental disabilities. Research in Developmental Disabilities, 15, 119-131.

Wehmeyer, M. L. (1994b). Perceptions of self-determination and psychological empowerment of adolescents with mental retardation. Education and Training in Mental Retardation and Developmental Disabilities, 29, 9-21.

Wehmeyer, M. L. (1994c). Reliability and acquiescence in the measurement of locus of control with adolescents and adults with mental retardation. Psychological Reports, 75, 527-537.

Wehmeyer, M. L. (1996a). Self-determination as an educational outcome: Why is it important to children, youth and adults with disabilities? In D. J. Sands \& M. L. Wehmeyer (Eds), Self-determination across the life span: Independence and choice for people with disabilities (pp. 15-34). Baltimore: Paul H. Brookes.

Wehmeyer, M. L. (1996b). Student self-report measure of selfdetermination for students with cognitive disabilities. Education and Training in Mental Retardation and Developmental Disabilities, 31, 282-293.

Wehmeyer, M. L. (1999). A functional model of selfdetermination: Describing development and implementing instruction. Focus on Autism and Other Developmental Disabilities, 14, 53-61.

Wehmeyer, M. L. (2001). Self-determination and mental retardation. In L. M. Glidden (Ed.), International review of research in mental retardation (Vol. 24, pp. 1-48). San Diego, CA: Academic Press.

Wehmeyer, M. L., Abery, B., Mithaug, D. E., \& Stancliffe, R. (2003). Theory in self-determination: Foundations for educational practice. Springfield, IL: Charles C. Thomas Publishing Company.

Wehmeyer, M. L., \& Kelchner, K. (1995). The Arc's SelfDetermination Scale. Arlington, TX: The Arc National Headquarters.

Wehmeyer, M. L., \& Kelchner, K. (1996). Perceptions of classroom environment, locus of control and academic attributions of adolescents with and without cognitive disabilities. Career Development for Exceptional Individuals, 19, 15-29.

Wehmeyer, M. L., \& Lopez, S. J. (2003). The Adolescent Self-Determination Assessment. Lawrence, KS: Kansas University Center on Developmental Disabilities.

Wehmeyer, M. L., Lopez, S. J., Shogren, K. A., \& Pressgrove, C. L. (2005). Psychometric properties of the Adolescent Self-Determination Assessment. Manuscript in preparation.

Wehmeyer, M. L., \& Palmer, S. (2003). Adult outcomes for students with cognitive disabilities three-years after high school: The impact of self-determination. Education and Training in Developmental Disabilities, 38, 131-144.

Wehmeyer, M. L., Palmer, S. B., Agran, M., Mithaug, D. E., \& Martin, J. E. (2000). Promoting causal agency: The selfdetermined learning model of instruction. Exceptional Children, 66, 439-453. 
Wehmeyer, M. L., \& Schwartz, M. (1997). Self-determination and positive adult outcomes: A follow-up study of youth with mental retardation or learning disabilities. Exceptional Children, 63, 245-255.

Wehmeyer, M. L., \& Schwartz, M. (1998). The relationship between self-determination and quality of life for adults with mental retardation. Education and Training in Mental Retardation and Developmental Disabilities, 33, 3-12.
Wehmeyer, M. L., Yeager, D., Bolding, N., Agran, M., \& Hughes, C. (2003). The effects of self-regulation strategies on goal attainment for students with developmental disabilities in general education classrooms. Fournal of Developmental and Physical Disabilities, 15, 79-91.

Whitman, T. L. (1990). Self-regulation and mental retardation. American fournal on Mental Retardation, 94, 347-362. 